\title{
METODOLOGIAS ATIVAS: UMA INOVAÇÃO NA DISCIPLINA DE FUNDAMENTOS PARA O CUIDADO PROFISSIONAL DE ENFERMAGEM
}

\author{
Luciara Fabiane Sebold' ${ }^{1}$ Fernanda Espíndola Martins² ${ }^{2}$ Rosiane da Rosa² ${ }^{2}$ Telma Elisa Carraro ${ }^{3}$, Jussara Gue Martini ${ }^{4}$,
} Silvana Silveira Kempfer ${ }^{5}$

RESUMO: Relato de experiência de discentes e docentes no desenvolvimento da Disciplina de Fundamentos para o Cuidado Profissional, da terceira fase do Curso de Graduação em Enfermagem da Universidade Federal de Santa Catarina. Participaram 36 acadêmicos e 10 professoras. Foram utilizadas Metodologias Ativas, aplicadas em diferentes cenários de ensino-aprendizagem. Os participantes foram divididos aleatoriamente em três grupos compostos por acadêmicos, um tutor e dois facilitadores. Cada grupo coletou dados em clínicas de internação do Hospital Universitário e elaborou um estudo de caso; em seguida, foram elaboradas questões de aprendizagem. Durante o processo, o educando foi estimulado a responder, com discussão teórico-prática coletiva, o que permitiu a ele transformar a realidade, e a participar ativamente na busca pelo conhecimento. Esta foi uma importante experiência, por ser uma forma diferenciada de ensinar-aprender que envolveu tanto os docentes quanto os discentes.

PALAVRAS-CHAVE: Educação; Cuidados de enfermagem; Aprendizagem.

\section{ACTIVE METHODOLOGIES: AN INNOVATION FOR THE DISCIPLINE OF PROFESSIONAL NURSING CARE FUNDAMENTALS}

\begin{abstract}
This is an experience report of students and teachers in developing the Discipline of Professional Nursing Care Fundamentals, of the third stage of the undergraduate program in Nursing at the Universidade Federal de Santa Catarina. The participants were 36 students and 10 teachers. Active methodologies were used, applied in different scenarios of teaching and learning. The participants were divided randomly into three groups composed of academics, mentors and two facilitators. Each group collected data on inpatient clinics of the University Hospital and developed a case study and then learning issues were prepared. During the process, the student was encouraged to respond, with theoretical discussion and practical conference, which allowed him to transform reality and to participate actively in the search for knowledge. This was an important experience, it was a different way of teaching-learning involving both teachers and learners.
\end{abstract}

KEYWORDS: Education, Nursing; Learning.

\section{METODOLOGÍAS ACTIVAS: UNA INNOVACIÓN EN LA DISCIPLINA DE FUNDAMENTOS PARA EL CUIDADO PROFESIONAL DE ENFERMERÍA}

RESUMEN: Relato de experiencia de discentes y docentes en desarrollo de la Disciplina de Fundamentos para el Cuidado Profesional de la tercera fase del Curso de Graduación en Enfermería de la Universidad Federal de Santa Catarina. Participaron 36 académicos y 10 profesoras. Fueron utilizadas Metodologías Activas, aplicadas en distintos escenarios de ensiñanza-aprendizaje. Los particpantes fueron organizados de modo aleatorio en tres grupos compuestos por académicos, un tutor y dos facilitadores. Cada grupo recogió datos en clínicas de internación del Hospital Universitario y elaboró un estudio de caso y, en seguida, fueron elaboradas cuestiones de aprendizaje. Durante el proceso, el educando fue estimulado a contestar, con discusión teórico-práctica colectiva, lo que permitió a él transformar la realidad y participar activamente en la búsqueda por el conocimiento. Esta fue una importante experiencia, a causa de ser una forma diferenciada de enseñar-aprender que involucró tanto a los docentes cuanto a los discentes.

PALABRAS CLAVE: Educación; Cuidados de enfermería; Aprendizaje.

'Enfermeira. Doutoranda do Programa de Pós-Graduação em Enfermagem da Universidade Federal de Santa Catarina-PPGEnf/ UFSC. Professora Substituta do Curso de Graduação em Enfermagem da UFSC. Membro do Grupo de Pesquisa Cuidando e Confortando-C\&C/UFSC.

${ }^{2}$ Acadêmica do Curso de Graduação em Enfermagem da UFSC.

${ }^{3}$ Enfermeira. Pós-doutor em Enfermagem. Professor do Departamento de Enfermagem e do PPGEnf/UFSC. Coordenador da Disciplina Fundamentos para o Cuidado Profissional. Líder do C\&C/UFSC.

${ }^{4}$ Enfermeira. Doutor em Educação. Professor Adjunto do Departamento de Enfermagem e do PPGEnf/UFSC.

${ }^{5}$ Enfermeira. Doutoranda do PPGEnf/UFSC. Professor Substituto da Disciplina Fundamentos para o Cuidado Profissional da UFSC. Membro do C\&C/UFSC.

\section{Autor correspondente:}

Luciara Fabiane Sebold

Universidade Federal de Santa Catarina

R. das Roseiras, 685 - 88108-460 - São José-SC-Brasil

Recebido: 27/11/09

E-mail: fabisebold@gmail.com

Aprovado: 29/08/10 


\section{INTRODUÇÃO}

Este relato de experiência tem como objetivo compartilhar a experiência vivenciada por discentes e docentes da terceira fase do Curso de Graduação em Enfermagem da Universidade Federal de Santa Catarina (UFSC), no desenvolvimento da Disciplina Fundamentos para o Cuidado Profissional, com a utilização de Metodologias Ativas em diferentes cenários de ensino-aprendizagem. Este tipo de metodologia tem por objetivo desenvolver as potencialidades dos alunos para que possam se assumir como protagonistas do processo de formação. Neste contexto, as Metodologias Ativas são inovadoras e, de certo modo, instigantes tanto para os docentes como para os discentes.

Um desafio de docentes consiste em compreender as ações pedagógicas e o papel que assumem no processo de ensinar e aprender, reconhecendo as demandas e os requerimentos que determinam o modo de ser e agir ${ }^{(1)}$. Assim, o movimento de reflexão passa a ser um fator importante no processo, visto ser desta forma que se questiona o cotidiano da educação. Portanto,

não é possível fazer reflexões acerca da educação sem refletir sobre o próprio homem. Que busca inovações, pois se reconhece como um ser inacabado e por isso se educa, na busca constante de ser mais, para melhor se adaptar ao meio. Isto seria a raiz da educação ${ }^{(2: 27)}$.

O homem, entendido como um ser político que está sempre em processo adaptativo, faz das mudanças parte de seu cotidiano, no qual o conhecimento é uma destas mudanças, considerando-se que a busca pelo conhecimento é uma aventura incerta que representa riscos de ilusão e de erro $^{(3)}$.

Observa-se que, no contexto moderno das tecnologias da educação, a aula tradicional (sala de aula) será cada vez mais dispensada, pois a disponibilidade do conhecimento estará ao alcance de todos ${ }^{(4)}$.

A Disciplina Fundamentos para o Cuidado Profissional foi cuidadosamente programada seguindo a proposta do ensino libertador/criativo, despertando nos docentes também a motivação necessária para inovar e buscar a liberdade de exercer a educação de forma mais livre e menos engessada. E, para que isso se efetivasse, era necessária a instrumentalização teórica e a criação de uma proposta didática própria, por meio do estudo das questões pedagógicas e de um embasamento filosófico, epistemológico e metodoló- gico que lhes dê suporte ${ }^{(5)}$.

O processo de construção da educação foi permeado por várias tendências e métodos de ensino. Os mesmos foram moldados conforme as necessidades impostas pela própria sociedade e por necessidades de adequação do "mundo de sala de aula" com o "mundo real", pois a transformação da realidade, segundo tendências tradicionais, não mais estava sendo apropriada para a sociedade moderna ${ }^{(6)}$, pois com a globalização o conhecimento passa a ser compartilhado com todos e em tempo real, exigindo adaptações tanto dos professores quanto dos próprios alunos.

Com as novas tendências, visualizamos um processo de interação entre educador e educando, nas quais estes criam conjuntamente novos métodos e caminhos de ensino-aprendizagem, levando à construção do conhecimento pelo próprio aluno, focando a questão da subjetividade e a formação de novos cidadãos. Baseado nestas novas tendências, a quantidade de conteúdo apreendida pelo educando se faz menos importante do que os métodos utilizados para o ensino ${ }^{(7)}$.

Dentro das novas tendências pedagógicas surgem as metodologias ativas de ensino-aprendizagem que são conceituadas como um meio que possibilita o aprender a aprender, centrando-se nos princípios da pedagogia interativa, crítica e reflexiva ${ }^{(8)}$. Estas metodologias desenvolvem a participação ativa dos educandos no processo dinâmico de construção do conhecimento, resolução e avaliação de problemas, trazendo o educando para o papel de sujeito ativo de seu crescimento, protagonista do processo.

Os docentes e os acadêmicos da terceira fase do Curso de Graduação em Enfermagem são entendidos, neste contexto, como sujeitos da práxis pedagógica, podendo ser chamados de educadores e educandos. São cidadãos comuns convivendo em um contexto sociocultural e compartilhando dos seus significados.

\section{Vivenciando Fundamentos de Enfermagem por meio das Metodologias Ativas}

No primeiro semestre do ano de 2006, aconteceu o primeiro contato com as metodologias ativas na Disciplina de Fundamentos para o Cuidado Profissional do Curso de Graduação em Enfermagem numa universidade pública do Sul do Brasil. É nesta disciplina que se aprende não apenas as principais técnicas de enfermagem, mas também as ações e conhecimentos 
envolvidos no processo de cuidar dos pacientes que se encontram internados em unidades do Hospital Universitário. Dentre os conteúdos, destacam-se a ética, o processo de trabalho, as teorias de Enfermagem, a metodologia do cuidado e os procedimentos básicos da enfermagem. Os conteúdos foram agrupados em unidades de conhecimento, conforme a complexidade.

No primeiro dia de aula, notou-se que o semestre seria diferente. Inicialmente, a turma foi dividida em três grupos, e cada grupo subdividido em dois subgrupos. Cada grupo contou com uma professora tutora, responsável pelo andamento do grupo no que diz respeito às discussões dos temas geradores e ao andamento dos trabalhos relacionados à disciplina; e duas professoras facilitadoras, responsáveis pelo acompanhamento diário das discussões das temáticas em sala de aula, nas aulas de laboratório de enfermagem (LABENF) e nos estágios supervisionados no Hospital Universitário.

No início de cada unidade de conhecimento, fez-se um levantamento de dados relacionados ao paciente, de modo a englobar as temáticas referentes a esta unidade, elencando as situações, para por meio dessas levantar as questões instigadoras de como se processavam determinadas condutas, o porquê das mesmas, entre outras.

Nesta primeira unidade de conhecimento, contemplaram-se alguns cuidados de enfermagem, como: assuntos relacionados com sinais vitais e dor, cuidados de higiene e conforto ao paciente, cuidados com a mecânica corporal, integridade cutâneo-mucosa, cuidados a pacientes com feridas e bandagens, exame físico e biossegurança.

A abordagem da primeira unidade de conhecimento foi iniciada numa manhã, sendo os subgrupos alocados em unidades de internação do HU, acompanhados pelas professoras facilitadoras. Naquele momento, foram realizadas entrevistas com os pacientes para daí ser composto o estudo de caso. A partir destes dados, os alunos foram incentivados pela professora tutora a montar um estudo de caso, discutindo as questões de aprendizagem referentes à primeira unidade de conhecimento, incluindo questões éticas observadas na unidade de internação. As questões de aprendizagem foram entendidas como o ponto de partida para a busca das respostas dos questionamentos levantados nas discussões. Os alunos buscaram subsídios teóricos para as discussões em sala de aula, com as tutoras e facilitadoras. Vale salientar que os alunos tinham alguns períodos pre- vistos no cronograma da disciplina para desenvolver estudos independentes.

Após as discussões em sala de aula e o aprofundamento teórico desenvolvido conjuntamente, realizou-se a socialização com a turma toda; cada grupo de tutoria apresentou seu estudo de caso, bem como respectivas questões de aprendizagem relativas à primeira unidade de conhecimento. Este foi um momento valioso devido às diferentes realidades, maneiras de ver e trabalhar com as mesmas, de cada subgrupo.

Posteriormente a esta discussão e socialização, os grupos retornaram ao $\mathrm{HU}$, na mesma unidade de internação, para oportunizar a observação das questões levantadas a partir das discussões de grupo. Assim, percebeu-se que a observação na Enfermagem é imprescindível para toda e qualquer situação de saúde-doença.

Concomitantes ao processo de discussão teórica, ocorreram aulas no LABENF, onde os alunos foram habilitados em desenvolver os procedimentos básicos que constavam das questões de aprendizagem daquela unidade de conhecimento.

Após o desenvolvimento dos conteúdos teórico-práticos em sala de aula e LABENF, iniciou-se a prática supervisionada no HU. Cada subgrupo foi acompanhado por uma professora facilitadora que, neste momento, atribuía as tarefas aos acadêmicos no cuidado ao paciente internado e sua família. Nesta ocasião, percebeu-se que as discussões em grupo contribuíam muito para o aprendizado, pois as oportunidades de contato com realidades distintas eram únicas e nos remetiam a reflexões acerca da Enfermagem e até mesmo de nossas próprias vidas.

Ao finalizar o primeiro contato com o hospital, percebeu-se que por meio das metodologias ativas pode-se ir muito além do "conteúdo ministrado em sala de aula" e apropriar-se de conhecimentos que estão disponibilizados em vários veículos de comunicação, remetendo a um mundo sem fronteiras e limites.

A segunda unidade de conhecimento englobou aspectos do conhecimento mais complexos, num crescente de aprendizagem. Envolveu os seguintes temas: ética; processo de morrer; cuidado de si; metodologia do cuidado; teorias de enfermagem e correntes de pensamento; relações interpessoais e exercício profissional; procedimentos e cuidados aos pacientes na administração de medicamentos; procedimento e cuidados aos pacientes em oxigenoterapia; procedimento e cuidados aos pacientes com sonda 
nasogástrica e nasoenteral; procedimento e cuidados aos pacientes com sonda vesical; procedimento e cuidados aos pacientes e suas eliminações.

No início desta unidade, retornou-se à Unidade de Internação do HU para coletar novos dados para o estudo de caso, envolvendo outras questões de aprendizagem. Em seguida, elaborou-se sínteses das questões de aprendizagem, levando-as para discussão.

Neste estágio, o período de contato com o paciente e família foi maior e, em decorrência disto, houve mais tempo para o seu desenvolvimento e treinamento de habilidades técnicas. Acreditamos que este resultado foi alcançado pela própria metodologia empregada na disciplina, através da qual a teoria subsidiou a prática.

Na terceira unidade de conhecimento discutiu-se algumas questões teóricas, abrangendo temas como sociedade e modos de produção, processo de trabalho, processo de pesquisa, cuidado integral, e saberes e práticas de enfermagem.

O comprometimento e o crescimento educacional e pessoal dos sujeitos envolvidos neste processo foram de grande importância para a identificação dos aspectos positivos e dos que precisavam ser reformulados nesta metodologia, pois o diálogo entre os docentes e discentes esteve presente nas mais variadas circunstâncias, balizando as relações de confiança e cumplicidade. E neste processo, a autoavaliação dos sujeitos ocorreu durante todo o processo, no qual o aluno tornara-se coparticipante de seu aprendizado e desempenho, oportunizando também o registro de conhecimentos e habilidades, conquistas e valores interiorizados; ao mesmo tempo, ampliou seu entendimento acerca do aprendizado, ultrapassando o conhecer e o fazer e aprendendo a viver em conjunto com o ser, estes, pressupostos da transdisciplinaridade ${ }^{(9)}$.

\section{CONSIDERAÇÕES FINAIS}

Assim, como todas as mudanças de postura, a implementação das metodologias ativas nesta fase de aprendizado propiciou muitas reflexões e ajustes, apresentando algumas dificuldades como a credibilidade dos acadêmicos de enfermagem no processo, pois algo novo, inovador, causa certa insegurança. Porém, a força de vontade e o entusiasmo dos discentes e docentes fizeram com que a proposta tivesse resultados positivos. Percebemos que os alu- nos assumiram-se como protagonista do processo de ensino-aprendizado, tendo o professor papel fundamental na busca de subsídios para contribuir com o crescimento acadêmico.

\section{REFERÊNCIAS}

1. Reibnitz KS, Prado ML. Inovação e educação em enfermagem. Florianópolis: Cidade Futura; 2006.

2. Freire P. Educação e mudança. 27 ed. Rio de Janeiro: Paz e Terra; 2003.

3. Morin E. Os sete saberes necessários à educação do futuro. Tradução de Catarina da Silva e Jeanne Sawaya. Revisão Técnica de Edgar de Carvalho. $3^{\text {a }}$ ed. São Paulo/Brasília: Cortez/UNESCO; 2001.

4. Demo P. Conhecer e aprender: sabedoria dos limites e desafios. Porto Alegre: Artes Médicas Sul; 2000.

5. Tacla MTGM. Desenvolvendo o pensamento crítico no ensino de enfermagem. Goiânia: AB; 2002.

6. Bagnato MHS. Concepções pedagógicas no ensino de enfermagem no Brasil. Texto \& Contexto Enferm.1997;6(3):241-58.

7. Berbel NAN, organizador. Metodologia da problematização: fundamentos e aplicações. Londrina: UEL; 1999.

8. Fernandes JD, Ferreira SL, La Torre MPS, Santa Rosa DO, Costa HOG. Estratégias para a implantação de uma nova proposta pedagógica na escola de enfermagem da Universidade Federal da Bahia. Rev Bras Enferm.200;56(4):392-5.

9. Krozeta K, Meier MJ, Danski MR. A auto-avaliação: uma possibilidade de mudança na formação profissional. Cogitare Enferm. 2008;13(4):612-5. 